\title{
Correlation between Abortion and Infertility among Nonsmoking Women with a History of Passive Smoking in Childhood and Adolescence
}

\author{
Jila Amirkhani, ${ }^{1}$ Soheila Yadollah-Damavandi, ${ }^{2}$ Seyed Mohammad-Javad Mirlohi, ${ }^{3}$ \\ Seyede Mahnaz Nasiri, ${ }^{3}$ Yekta Parsa, ${ }^{2}$ and Mohammad Gharehbeglou ${ }^{4}$ \\ ${ }^{1}$ Medical Science Research Center, Medical Department, Islamic Azad University, Tehran Medical Sciences Branch, Tehran, Iran \\ ${ }^{2}$ Young Researchers Club, Islamic Azad University, Tehran Medical Sciences Branch, Tehran, Iran \\ ${ }^{3}$ Student Research Committee, Islamic Azad University, Tehran Medical Sciences Branch, Tehran, Iran \\ ${ }^{4}$ Department of Medicine, Islamic Azad University, Qom Branch, Qom, Iran
}

Correspondence should be addressed to Yekta Parsa; yekta.parsa@gmail.com

Received 17 May 2014; Revised 9 July 2014; Accepted 30 July 2014; Published 13 August 2014

Academic Editor: Stefania A. Nottola

Copyright (c) 2014 Jila Amirkhani et al. This is an open access article distributed under the Creative Commons Attribution License, which permits unrestricted use, distribution, and reproduction in any medium, provided the original work is properly cited.

The aim of this study is to evaluate the correlation of exposing to the cigarette smoke in childhood and adolescence with infertility and abortion in women. This case-control study evaluated 178 women who had been attended to at the Amir-al-Momenin Hospital in Tehran in 2012-2013. Seventy-eight women with chief complaint of abortion, infertility, and missed abortion and 100 healthy women were considered as case and control groups, respectively. The tool was a questionnaire with two parts. In the first part demographic information was gathered and in the second part the information regarding the history of passive smoking in childhood and adolescence period, abortion, and infertility was gathered. The mean age in case and control groups was 26.24 \pm 3.1 and $27.3 \pm 4.2$ years, respectively. The mean body mass index $(\mathrm{BMI})$ was $25.74 \pm 1.38 \mathrm{Kg} / \mathrm{m}^{2}$. Abortion rates among passive smoker and nonpassive smoker patients were statistically significant $(P=0.036)$. Based on findings of this study, the experience of being a passive smoker in childhood and adolescence in women will increase the risk of abortion and infertility in the future, which could be the reason to encourage the society to step back from smoking cigarettes.

\section{Introduction}

Currently, smoking is one of the most important causative factors in human death. World annual death among smokers is more than 4 million, which is predicted to reach 10 million in 2020 without interfering [1-3]. There are more than 10 million smokers in Iran, of those, $2.5 \%$ are women. Even though the cigarette consumption is higher among males, it is predicted to be equal in the near future, regarding the habitual change in society [4]. Cigarette has more than 4000 antigenic and carcinogenic factors such as cyclic aromatic benzene, cadmium, ethylbenzene, cotinine, and nicotine [5]. In some studies, it was shown that the risk of exposure to cancerous substances in passive smokers is 2.5 times more than the risk in direct smokers $[6,7]$. Pregnant women are more susceptible to the injuries and smokes. There are studies in benefit of preterm birth and low birth weight, related to passive smoking [8]. The immature and low-birth-weight neonates need special care and budget, and these babies are susceptible to have anatomical and mental damage in the future [8]. Cigarette is one of the agents that have potential risk to cause abortion and infertility. Abortion means the termination of pregnancy before the fetus reaches viability. Infertility is a condition in which a woman has not become pregnant after one year of regular sexual intercourse, without contraception $[9,10]$. Studies showed that cigarette smoking in 2 last months of pregnancy increases the risk of preterm birth and stillbirth [11]. Direct exposure to the cigarette smoke in women caused unsuccessful pregnancy, delay in fertilization, ectopic pregnancy, and placental defects. The nicotine in cigarette might affect the follicular growth negatively, by inducing apoptosis. On the other hand, the chemical agents 
in cigarette might affect function of the fallopian tubes. Menstrual disorders and premature menopause are also the other side effects of smoking, which might cause infertility [12-20]. Some studies in the United States demonstrated the effects of cigarette smoke on granulosa cells and aromatase enzyme that decreases the production of estrogen. In addition, the alkaloids in cigarette inhibit the production of progesterone [15]. In another study, hyperplasia of syncytial cells and cytotrophoblasts beside the false nodes in the umbilical cord and thickening of the basal membrane of placenta induced by cigarette smoke might cause the necrosis and abruption placentae have been reported [11]. Other effects of cigarette smoke during pregnancy include missed abortion, placenta previa, premature rupture of the amniotic membrane, increasing risk of fetal death after 12 weeks of pregnancy, and bleeding [21]. Regardless of physical and mental problems, abortion is responsible for 15-20\% of maternal death; it places a huge economic burden on healthcare system, especially in developing countries [8]. Knowing the factors like cigarette which leads to infertility and abortion is very important for the healthcare system. It is also essential to consider those factors in their planning to decrease the abortion and infertility rates. Therefore, the aim of this study is to evaluate the correlation of exposing to the cigarette smoke in childhood and adolescence with infertility and abortion in women.

\section{Methods and Materials}

This case-control study was performed on 178 nonsmoker women who had been attended to at Amir Hospital, Tehran, Iran, during 2012-2013. Seventy-eight women with chief complaint of abortion, infertility, and missed abortion and 100 healthy women were considered as case and control groups, respectively. Patients over 40 years with the history of genital infectious diseases, systemic diseases, metabolic disorders, recurrent miscarriage (the loss of three or more consecutive pregnancies), drug addiction, using antidepressants, and an anatomic disorder of uterus and ovaries were excluded from the study. A questionnaire consisting of two parts was prepared; the first part was dedicated to the demographic information and, in the second part, information about experience of cigarette smoking, being a passive smoker, and having experience of missed abortion and infertility was gathered.

Data were analyzed by statistical SPSS15 software, using chi-square test. The significant level was considered $P<0.05$.

\section{Results}

The mean age in case and control groups was $26.24 \pm 3.1$ and $27.3 \pm 4.2$ years, respectively. The mean body mass index (BMI) was $25.74 \pm 1.38 \mathrm{~kg} / \mathrm{m}^{2}$. Among the participants, $85.4 \%$ were housewives. In the case group, $71.7 \%(n=56)$ and, in the control group, $44 \%(n=44)$ were passive smokers.

According to Table 1, abortion rates among passive smoker and nonpassive smoker patients were statistically significant $(P=0.036)$; also, the difference between infertility rate in the two groups was statistically significant $(12.5 \%$
TABLE 1: The frequency of abortion and infertility in the case group with positive or negative history of passive smoking in childhood and adolescent.

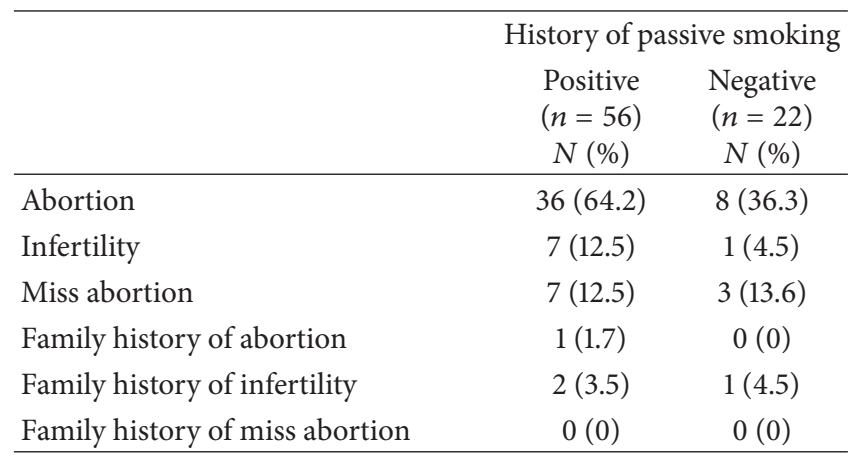

versus $4.5 \%$, resp., $P=0.02$ ), while there was not a significant correlation between family histories of abortion and missed abortion in patients $(P=0.84)$. There was no significant correlation between family history of abortion and infertility $(P=0.65)$ and family history of infertility with abortion in patients $(P=0.71)$. In addition, the correlation between family history of infertility and infertility in patients was not seen $(P=0.93)$.

\section{Discussion}

Cigarette smoking causes unsatisfactory changes in female's genital system, which is due to substances like nicotine that produce oxidative stress. Therefore, oxidative stress not only causes infertility, but also increases the risk of missed abortion as well. In animal studies, higher rate of abortion among passive smokers has been reported. The lowest rate of fertility compared to nonsmoker mice also has been reported [6].

In this study, $71.7 \%$ of participants were passive smokers. $64.2 \%$ of passive smokers and $36.3 \%$ of those with no experience of cigarette contact had an abortion, and the difference was statistically significant $(P=0.002)$. It was also a report of infertility among $12.5 \%$ of passive smokers and $4.5 \%$ of those without cigarette contact, in which the difference was statistically significant $(P=0.02)$. In a study by Meeker et al. in 2007 in the United States, the risk for the abortion among women who were passive smokers in comparison to others was 4.35 times higher, and the fertility rate was lower [22], which is similar to the current study. In another study by Neal et al., the same lower rate of fertility among active and passive smoker women was shown [23].

In a study by Depa-Martynów et al., the success rates of in vitro fertilization (IVF) among smoker women in comparison to control group were lower [24]. On the other hand, in the study by Sterzik et al., the success rates of IVF among infertile smoker women and passive smoker women were the same as the control group [25], which is different from the current study.

In a study by George et al., 19\% of women without experience of abortion and $24 \%$ of women with experience of abortion were passive smokers, which was statistically significant [26]. 
Cigarette smoking is a high-risk behavior which can lead to many social problems [27], as Patrick et al. [28] state that it causes premature morbidity and mortality. As a result, gathering data about this behavior seems to be necessary. Selfreports of smoking are usually conducted to see tendencies in cigarette smoking [29] and whether or not interventions towards this habitual desire are effective [28]. The validity of self-reported smoking is usually compromised by many reasons. For example, Patrick et al. [28] mention that smokers often deny or underestimate their smoking and its quantity. Another point of view is established by Pokorski et al. [30], which indicates that smoking is often an occasional habit among adolescents; therefore estimating the exact amount and pattern of smoking is not easy, as well. People may also be embarrassed by finding themselves as someone who commits an action which is not well accepted and desirable in the society; this can prevent them from reporting their information accurately and creating bias in smoking selfreports [27-30].

\section{Conclusion}

In conclusion, according to results of this study and compared to other studies, it seems that the experience of being passive smoker in childhood and adolescence will increase the risk of abortion and infertility in the future, and informing the society about the disadvantages of cigarette is recommended.

\section{Conflict of Interests}

The authors declare that there is no conflict of interests regarding the publication of this paper.

\section{References}

[1] M. M. Haenle, S. O. Brockmann, M. Kron et al., "Overweight, physical activity, tobacco and alcohol consumption in a crosssectional random sample of German adults," BMC Public Health, vol. 6, article 233, 2006.

[2] World Health Organization, Process for a Global Strategy on Diet Physical Activity and Health Geneva, World Health Organization, Geneva, Switzerland, 2003.

[3] J. I. Herrero, F. Pardo, D. D’Avola et al., "Risk factors of lung, head and neck, esophageal, and kidney and urinary tract carcinomas after liver transplantation: the effect of smoking withdrawal," Liver Transplantation, vol. 17, no. 4, pp. 402-408, 2011.

[4] K. Schilling, B. Toth, S. Rösner, T. Strowitzki, and T. Wischmann, "Prevalence of behaviour-related fertility disorders in a clinical sample: results of a pilot study," Archives of Gynecology and Obstetrics, vol. 286, no. 5, pp. 1307-1314, 2012.

[5] J. D. Meeker and M. D. Benedict, "Infertility, pregnancy loss and adverse birth outcomes in relation to maternal secondhand tobacco smoke exposure," Current Women's Health Reviews, vol. 9, no. 1, pp. 41-49, 2013.

[6] L. N. Anderson, M. Cotterchio, L. Mirea, H. Ozcelik, and N. Kreiger, "Passive cigarette smoke exposure during various periods of life, genetic variants, and breast cancer risk among never smokers," The American Journal of Epidemiology, vol. 175, no. 4, pp. 289-301, 2012.
[7] K. S. Louie, X. Castellsague, S. De Sanjos et al., "Smoking and passive smoking in cervical cancer risk: pooled analysis of couples from the IARC multicentric case-control studies," Cancer Epidemiology Biomarkers and Prevention, vol. 20, no. 7, pp. 1379-1390, 2011.

[8] C. Iñiguez, F. Ballester, R. Amorós, M. Murcia, A. Plana, and M. Rebagliato, "Active and passive smoking during pregnancy and ultrasound measures of fetal growth in a cohort of pregnant women," Journal of Epidemiology \& Community Health, vol. 66, no. 6, pp. 563-570, 2012.

[9] S. Gurunath, Z. Pandian, R. A. Anderson, and S. Bhattacharya, "Defining infertility-a systematic review of prevalence studies," Human Reproduction Update, vol. 17, no. 5, Article ID dmr015, pp. 575-588, 2011.

[10] C. Gnoth, E. Godehardt, P. Frank-Herrmann, K. Friol, J. Tigges, and G. Freundl, "Definition and prevalence of subfertility and infertility," Human Reproduction, vol. 20, no. 5, pp. 1144-1147, 2005.

[11] L. B. Strand, A. G. Barnett, and S. Tong, "Maternal exposure to ambient temperature and the risks of preterm birth and stillbirth in Brisbane, Australia," The American Journal of Epidemiology, vol. 175, no. 2, pp. 99-107, 2012.

[12] R. Bordel, M. W. Laschke, M. D. Menger, and B. Vollmar, "Nicotine does not affect vascularization but inhibits growth of freely transplanted ovarian follicles by inducing granulosa cell apoptosis," Human Reproduction, vol. 21, no. 3, pp. 610-617, 2006.

[13] S. R. Soares and M. A. Melo, "Cigarette smoking and reproductive function," Current Opinion in Obstetrics and Gynecology, vol. 20, no. 3, pp. 281-291, 2008.

[14] R. Shao, S. Zou, X. Wang et al., "Revealing the hidden mechanisms of smoke-induced fallopian tubal implantation," Biology of Reproduction, vol. 86, no. 4, article 131, 2012.

[15] A. Kokcu, "Premature ovarian failure from current perspective," Gynecological Endocrinology, vol. 26, no. 8, pp. 555-562, 2010.

[16] L. D. Dorn, S. Negriff, B. Huang et al., "Menstrual symptoms in adolescent girls: association with smoking, depressive symptoms, and anxiety," Journal of Adolescent Health, vol. 44, no. 3, pp. 237-243, 2009.

[17] W. C. Strohsnitter, E. E. Hatch, M. Hyer et al., "The association between in utero cigarette smoke exposure and age at menopause," American Journal of Epidemiology, vol. 167, no. 6, pp. 727-733, 2008.

[18] K. D. Henderson, L. Bernstein, B. Henderson, L. Kolonel, and M. C. Pike, "Predictors of the timing of natural menopause in the multiethnic cohort study," The American Journal of Epidemiology, vol. 167, no. 11, pp. 1287-1294, 2008.

[19] J. L. V. Shaw, E. Oliver, K. Lee et al., "Cotinine exposure increases fallopian tube PROKR1 expression via nicotinic AChR $\alpha-7$ : a potential mechanism explaining the link between smoking and tubal ectopic pregnancy," American Journal of Pathology, vol. 177, no. 5, pp. 2509-2515, 2010.

[20] J. Leonardi-Bee, A. Smyth, J. Britton, and T. Coleman, "Environmental tobacco smoke and fetal health: systematic review and meta-analysis," Archives of Disease in Childhood: Fetal and Neonatal Edition, vol. 93, no. 5, pp. F351-F361, 2008.

[21] M. H. Aliyu, O. Lynch, R. E. Wilson et al., "Association between tobacco use in pregnancy and placenta-associated syndromes: a population-based study," Archives of Gynecology and Obstetrics, vol. 283, no. 4, pp. 729-734, 2011. 
[22] J. D. Meeker, S. A. Missmer, D. W. Cramer, and R. Hauser, "Maternal exposure to second-hand tobacco smoke and pregnancy outcome among couples undergoing assisted reproduction," Human Reproduction, vol. 22, no. 2, pp. 337-345, 2007.

[23] M. S. Neal, E. G. Hughes, A. C. Holloway, and W. G. Foster, "Sidestream smoking is equally as damaging as mainstream smoking on IVF outcomes," Human Reproduction, vol. 20, no. 9, pp. 2531-2535, 2005.

[24] M. Depa-Martynów, L. Pawelczyk, G. Taszarek-Hauke, M. Jósiak, K. Derwich, and P. Jedrzejczak, "The effect of smoking on infertility treatment in women undergoing assisted reproduction cycles," Przegląd Lekarski, vol. 62, no. 10, pp. 973-975, 2005.

[25] K. Sterzik, E. Strehler, M. De Santo et al., "Influence of smoking on fertility in women attending an in vitro fertilization program," Fertility and Sterility, vol. 65, no. 4, pp. 810-814, 1996.

[26] L. George, F. Granath, A. L. V. Johansson, G. Annerén, and S. Cnattingius, "Environmental tobacco smoke and risk of spontaneous abortion," Epidemiology, vol. 17, no. 5, pp. 500-505, 2006.

[27] N. D. Brener, J. O. G. Billy, and W. R. Grady, "Assessment of factors affecting the validity of self-reported health-risk behavior among adolescents: evidence from the scientific literature," Journal of Adolescent Health, vol. 33, no. 6, pp. 436-457, 2003.

[28] D. L. Patrick, A. Cheadle, D. C. Thompson, P. Diehr, T. Koepsell, and S. Kinne, "The validity of self-reported smoking: a review and meta-analysis," The American Journal of Public Health, vol. 84, no. 7, pp. 1086-1093, 1994.

[29] S. L. Wong, M. Shields, S. Leatherdale, E. Malaison, and D. Hammond, "Assessment of validity of self-reported smoking status," Health Reports, vol. 23, no. 1, pp. 47-53, 2012.

[30] T. L. Pokorski, W. W. Chen, and R. L. Bertholf, "Use of urine cotinine to validate smoking self-reports in U.S. Navy recruits," Addictive Behaviors, vol. 19, no. 4, pp. 451-454, 1994. 


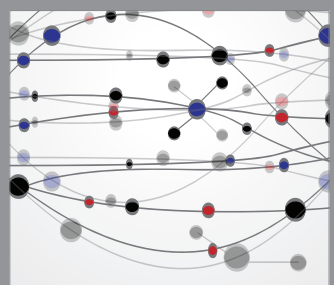

The Scientific World Journal
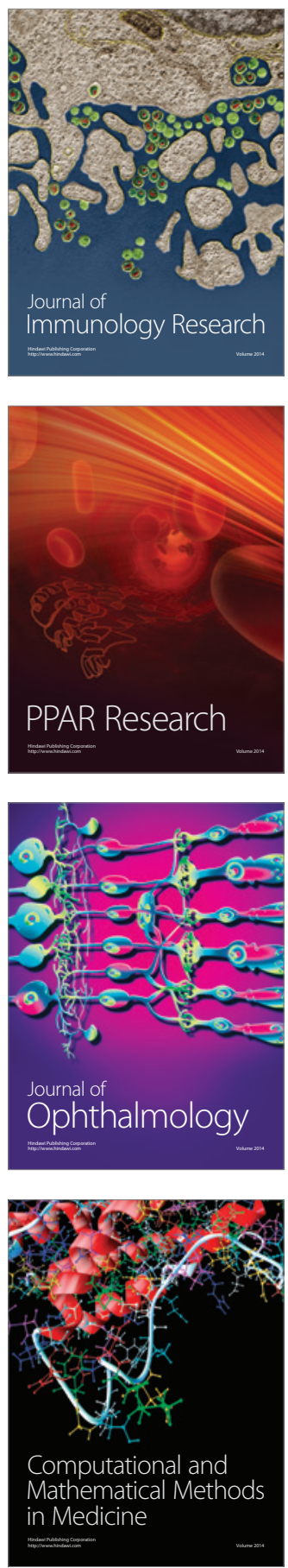

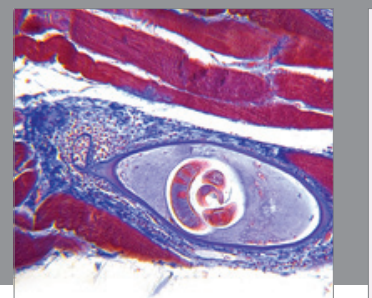

Gastroenterology

Research and Practice
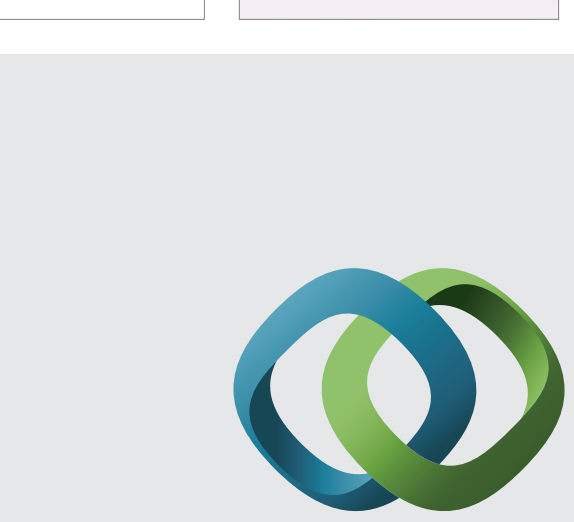

\section{Hindawi}

Submit your manuscripts at

http://www.hindawi.com
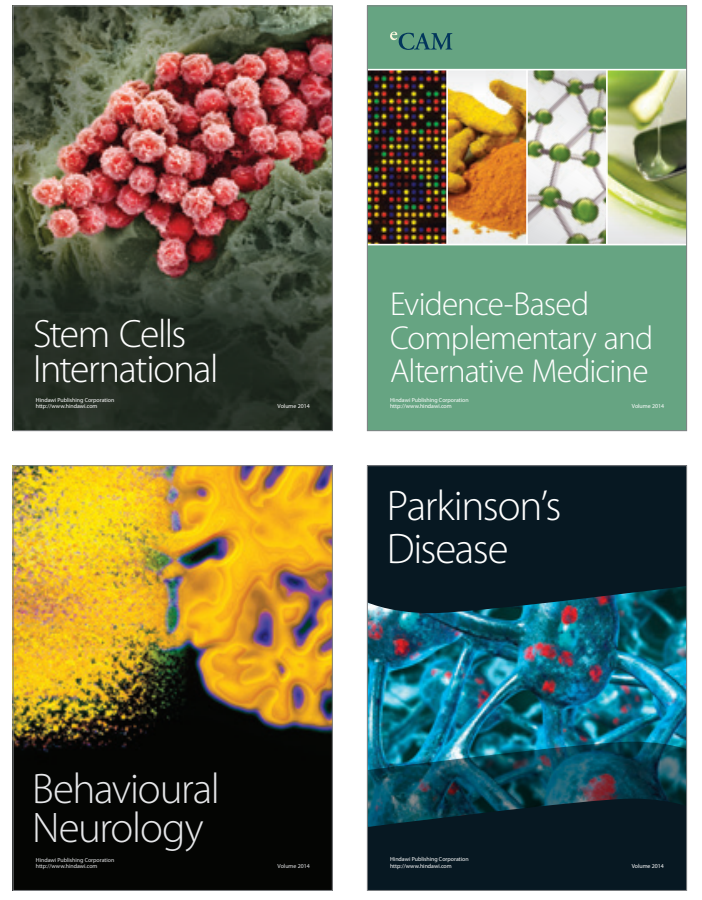
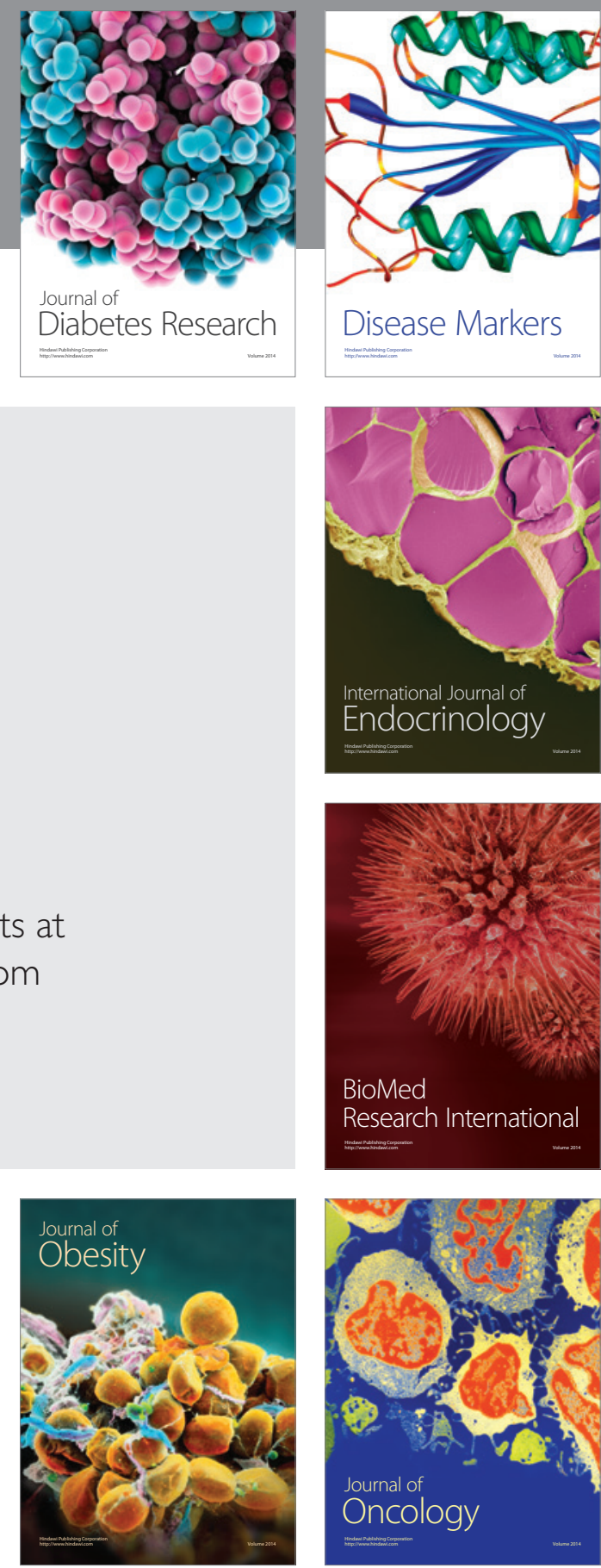

Disease Markers
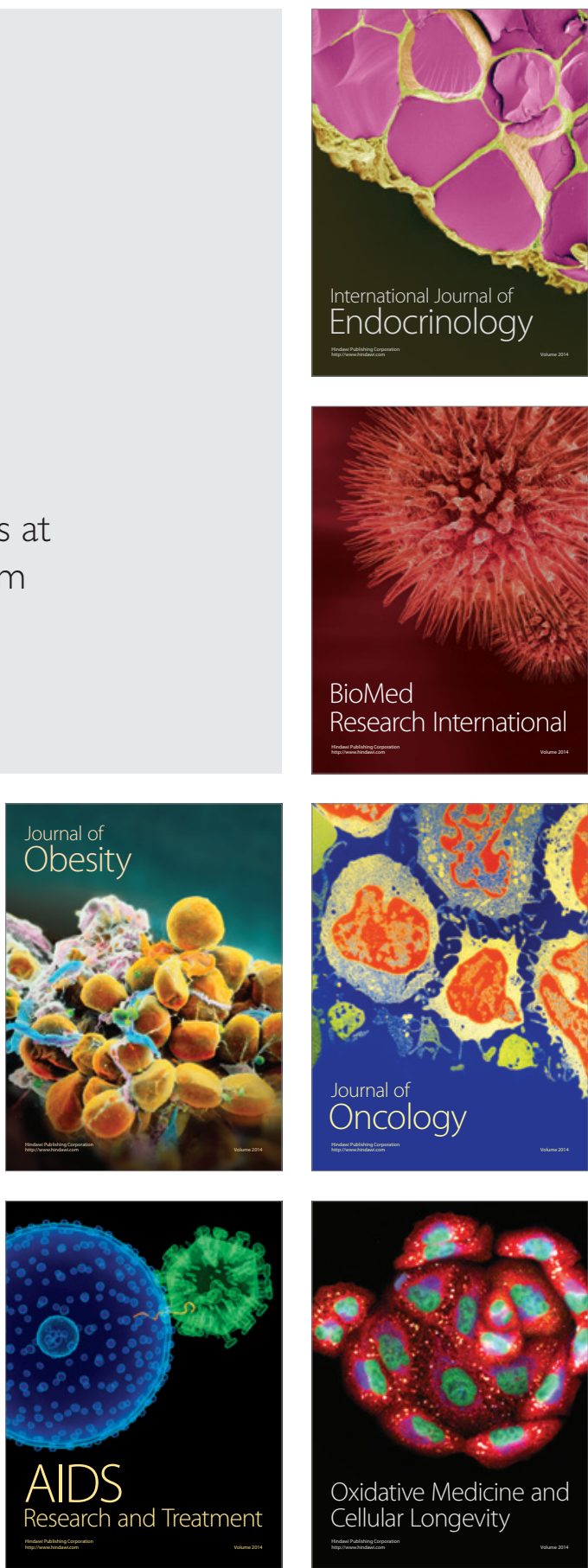